\title{
Drought assessment based on the number of days without precipitation
}

\author{
M. Zeleňáková ${ }^{1}$, M. Stračárová ${ }^{1}$, V. O. Harbul'áková ${ }^{1}$, \\ H. Hlavatá ${ }^{2} \&$ P. Purcz ${ }^{3}$ \\ ${ }^{1}$ Institute of Environmental Engineering, \\ Technical University of Košice, Slovakia \\ ${ }^{2}$ Slovak Hydrometeorological Institute, Slovakia \\ ${ }^{3}$ Institute of Construction Technology and Management, \\ Technical University of Košice, Slovakia
}

\begin{abstract}
When extreme and non-extreme physical events, such as drought, can affect elements of human systems in an adverse manner, it assumes the characteristic of a hazard. Droughts are the most complex but least understood of all natural hazards. It is broadly defined as a "severe water shortage". The objective of this paper was to investigate the number of days without precipitation during 30 years in chosen climatic stations in the eastern Slovakia. The results of the research proved that the occurrence of a drought in Slovakia is rare although periods longer than 30 days without precipitation were detected. This research may be helpful as one of the documents for water management practice, for example, for proposals of water harvesting in the country, the designing of other water structures or agricultural practices in the study area. The study of drought assessment is performed with the main goal of reducing negative impacts of droughts.

Keywords: dry period, extremes, precipitation, wet period.
\end{abstract}

\section{Introduction}

Variability of weather causes different substitution of dry and wet periods, e.g. groups of days, months, seasons or years (Paulson et al. [1]). Knowing the probability of occurrence of each period has extraordinary economic importance, especially in relation to other climatic factors, e.g. the temperatures. Data on the incidence and duration of dry and wet periods are usually expressed by statistical 
methods and the results are subjected to analysis (Bičárová et al. [2]). Scientists are trying to discover in substitution of dry and wet periods, the regularity or periodicity (Parajka et al. [3]). Most often they are looking for the relationship with 11-year period of sunspots (Pekárová et al. [4]). Other times the shorter periods $-3,7$ and 8 years are used. The task of this research is to find regularity of these changes and use it successfully.

Drought causes great damage to the national economy. Knowledge of principles and parameters allows preparation of appropriate measures to improve water management balances in dry periods. Analysis of drought allows the rational use of water resources and improves the efficiency of water management and national economic activity. Drought risk can be minimized or eliminated if we have a large enough volume of water supplies at a critical time.

Temperatures and precipitation trends and dryness/wetness pattern in the Zhujiang River Basin in South China during 1961-2007 were investigated by Fischer et al. [5]. Spatial distribution and temporal trends in precipitation extremes over the Hengduan Mountains region in China from 1961-2012 were investigated by Zhang et al. [6]. Nastos and Zerefos [7] analyze spatial and temporal variability of consecutive dry and wet days in Greece. Villafuerte II et al. [8] analyze longterm trends and variability of rainfall extremes in the Philippines. In Slovakia the distribution and trends of precipitation was studied by Kohnová et al. [9], Szolgay et al. [10], Zeleňáková et al. [11, 12].

This paper is devoted to the analysis of extreme climatic periods in the south eastern part of Slovakia - particularly the east Slovakian lowland - to analyse the occurrence of dry periods in four climatic stations in the river basin Bodrog, namely Humenné, Michalovce, Horovce and Vel'ké Kapušany. We evaluated dry periods for 31 years (1980-2011) at these stations.

\section{Study area}

The territory of Slovakia is, in the light of global climate classification, in the northern temperate climatic zone with a regular alternation of four seasons and variable weather, with a relative distribution of rainfall throughout the year. The study area is situated in the east Slovakian lowland. We evaluated the number of dry days in four climatic stations Humenné, Michalovce, Horovce and Vel'ké Kapušany (Figure 1). The daily precipitation data from the stations were obtained from the Slovak Hydrometeorological Institute (SHMI) during the period from 1980 to 2011.

Daily precipitations in $\mathrm{mm}$ were measured by standard rain gauge with an opening $500 \mathrm{~cm}^{2}$, which is elevated one meter above the ground. Climatic stations are part of a national network of the Slovak Hydrometeorological Institute.

For all four stations we analyzed the number of dry periods. The figures present the dry seasons - drought frequency in the range of one to several days associated with the longest drought. Drought is considered to be the number of consecutive days without precipitation. We divided the duration of dry periods into the following categories [13]: 


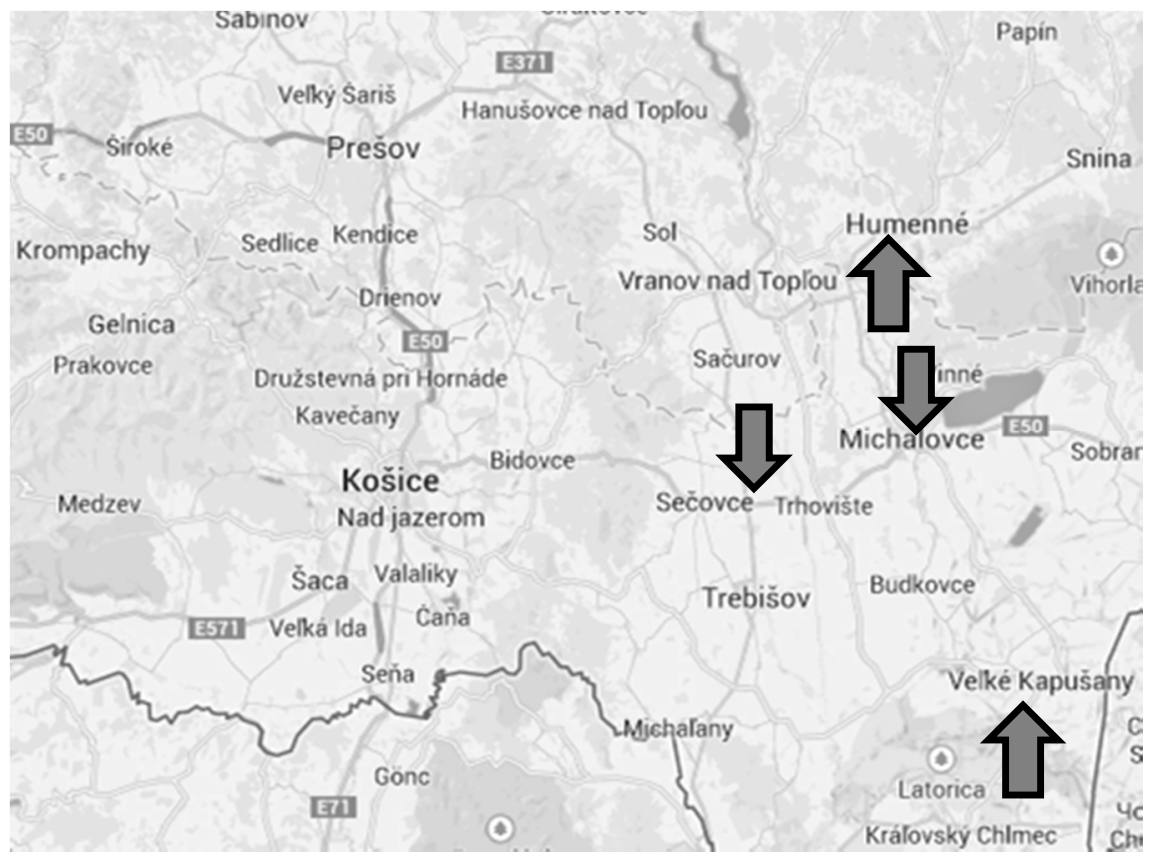

Figure 1: Location of rain gauge stations in eastern Slovakia.

- $\mathrm{ST}$ - short-term of dry period of a length in the range from 1 to 5 days,

- MT - medium-term dry period with a length of between 6-10 days,

- LT - long-term period with a duration of 11 days or more.

For each station we subsequently produced graphs of dry periods, which contain the sum of the individual categories ST, MT, or LT and graphs of the absolute value of dry periods.

\section{Results}

The frequency of observed periods without rainfall in the climatic stations for the period 1980 to 2011 is depicted in Figures 2-5.

Figure 2 shows the results from station Humenné (148 $\mathrm{m}$ asl), which is at the highest altitude of the four selected stations. The left column in the figure presents the number of continuous days without precipitation; the right column presents the sum of days in each category (ST, MT, LT) and the absolute sum of dry periods for the evaluated 31 years. The separate columns represent individual years. For example, a period of 4 consecutive dry days occurred ten times in 1981, in 19916 consecutive days without rain occurred four times, etc. The total sum of short-term drought occurred 1613 times, medium-term drought occurred 272 times, and long term dry periods occurred 83 times. The figure also shows that the absolute number of dry periods at this station for the period from 1980 to 2011 was 1968. The longest drought lasted 37 consecutive days, and this occurred in 2005. 


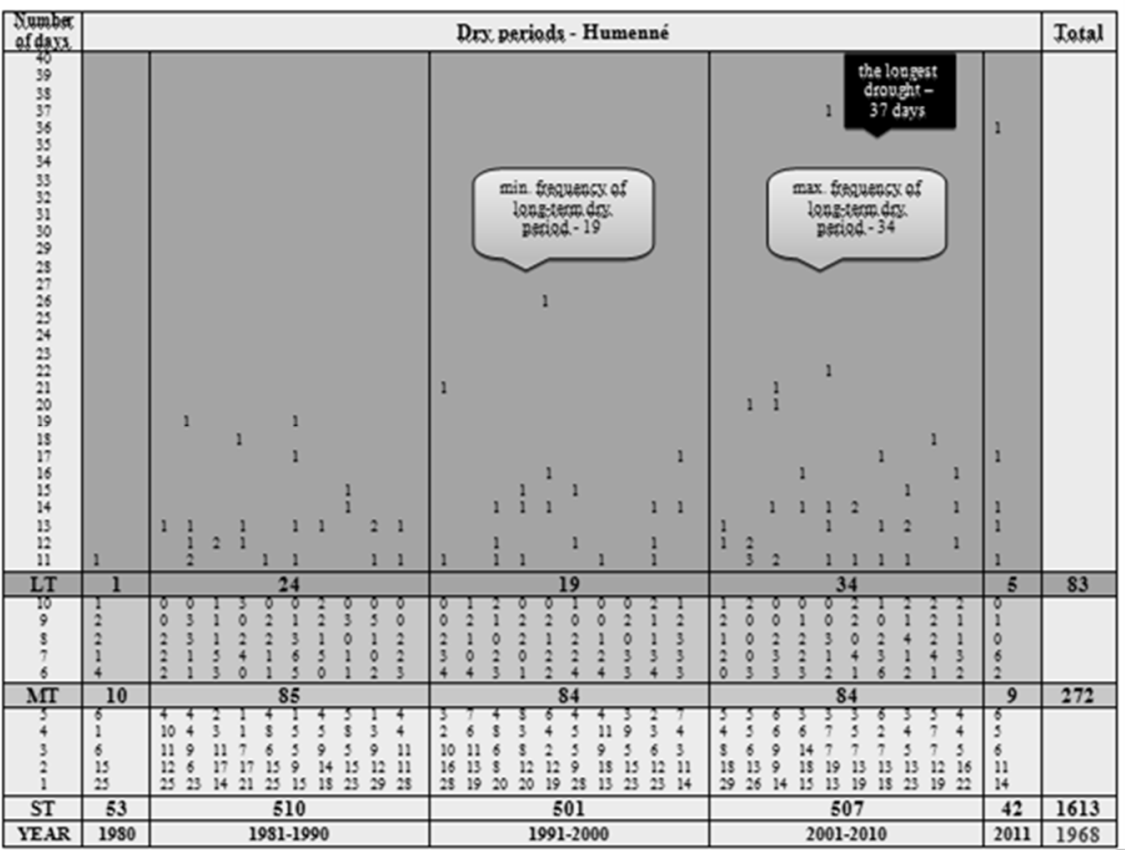

Figure 2: The frequency of dry periods in the years 1980-2011, the station Humenné.

In Figure 3 the frequency of droughts for the period 1980 to 2011 in the station Michalovce (111 m asl) is recorded. The left column is the number of continuous days without precipitation; the right column presents the sum of days in each category and the sum of the absolute dry days of the period. The separate columns represent individual years, for example a period of 3 consecutive dry days occurred ten times in 1985, in 20019 consecutive days without precipitation happened four times, etc. The total sum of short-term drought was 1598 times, medium-term drought occurred 302 times and long-term drought occurred 84 times. Figure 3 shows that the absolute number of dry days observed at this station over the period was 1984, the longest drought lasted for 36 consecutive days, and this was observed in 2011.

In Figure 4 the frequency periods without rainfall for the period 1980 to 2011 in the station Vel'ké Kapušany $(110 \mathrm{~m}$ asl $)$ are recorded. Figure 4 shows, for example, that a period of 2 consecutive days without rainfall occurred seventeen times in 1985, 6 consecutive days without rain happened four times in 1991, etc. The total sum of short-term drought was 1578 times, medium-term drought occurred 289 times and long dry periods occurred 89 times. Figure 4 also shows that the absolute number of dry days measured at this station for the period from 1980 to 2011 was 1956 , the longest drought lasted only 28 consecutive days, and this dry period occurred in 1983. 


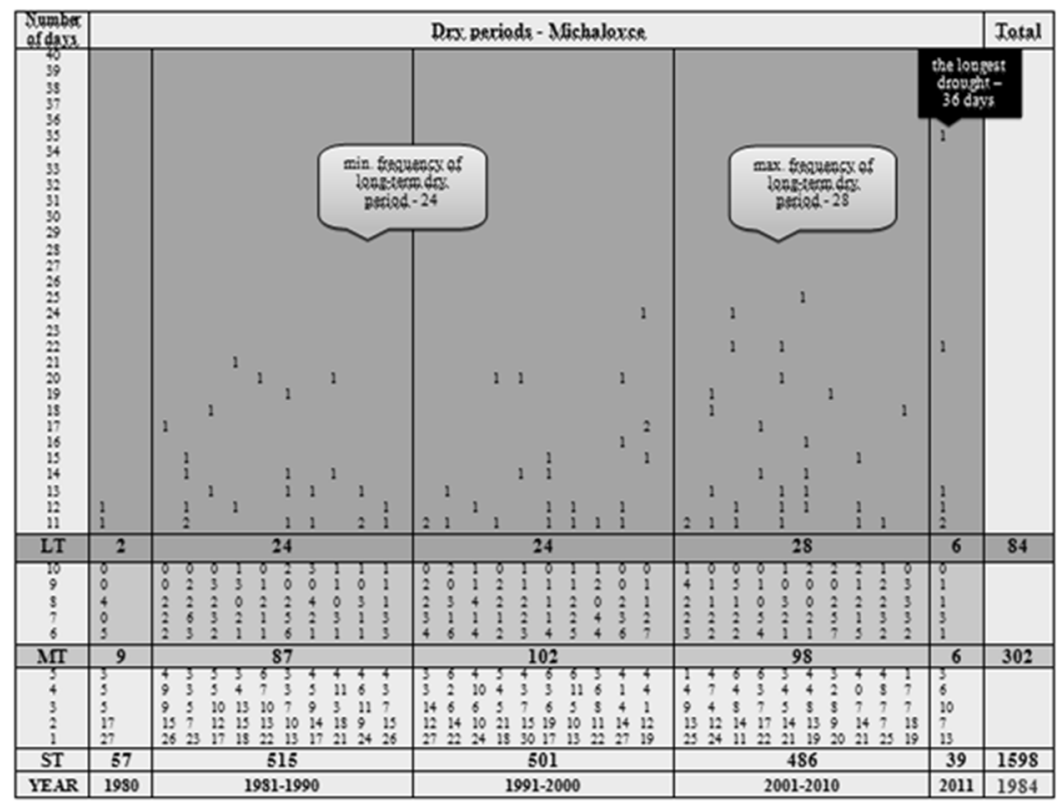

Figure 3: The frequency of droughts in the years 1980-2011, the station Michalovce.

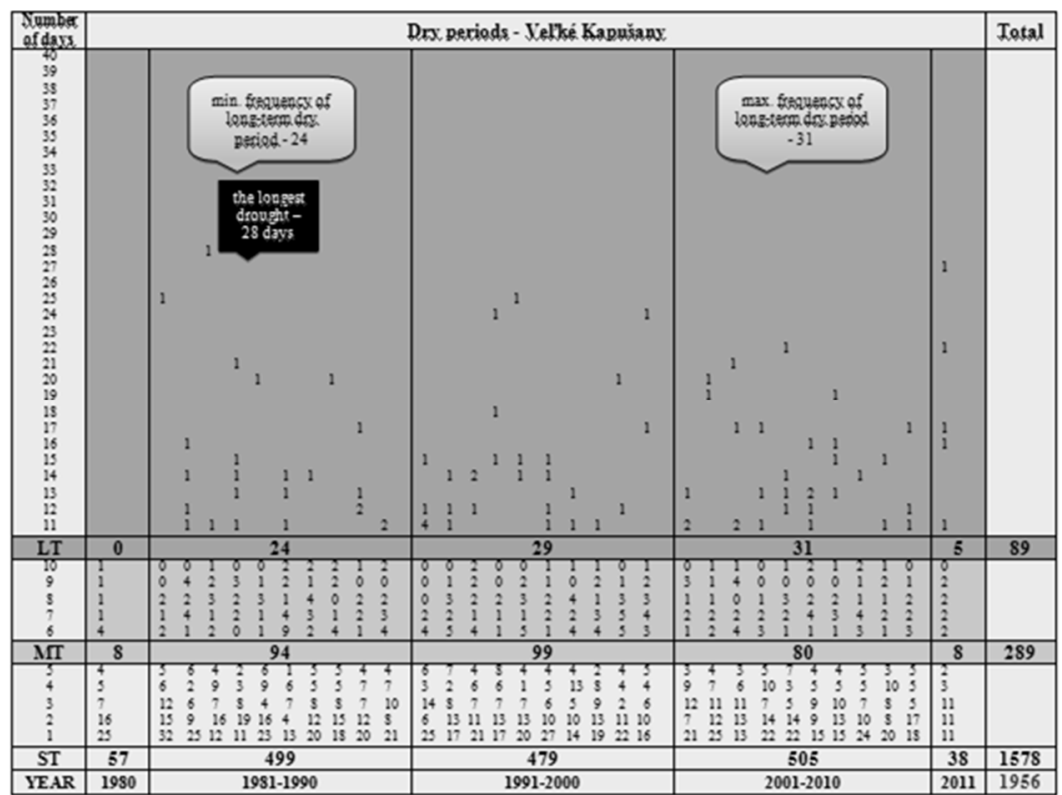

Figure 4: The frequency of droughts in the years 1980-2011, station Vel'ké Kapušany. 
In Figure 5 the frequency periods without precipitation in Horovce station (105 $\mathrm{m}$ asl) are recorded. This station is at the lowest altitude from the assessed stations although there is not a big difference between them. The left column again presents the number of continuous days without precipitation; the right column presents the sum of days in each category and the absolute sum of dry days for a given period of time. Separate columns again represent individual years. For example, a period of 5 consecutive dry days occurred nine times in 1981, 6 consecutive days without rain occurred five times in 1991, etc. The total sum of short-term drought occurred 1466 times, medium-term drought 292 times and long-term drought occurred 122 times. Figure 5 also shows that the absolute number of dry periods observed at this station for the period from 1980 to 2011 was 1880 . The longest drought lasted up to 99 consecutive days and this value was observed in 2009. This long period of drought lasted from 28th June to 5th October 2009 and was only observed at this station.

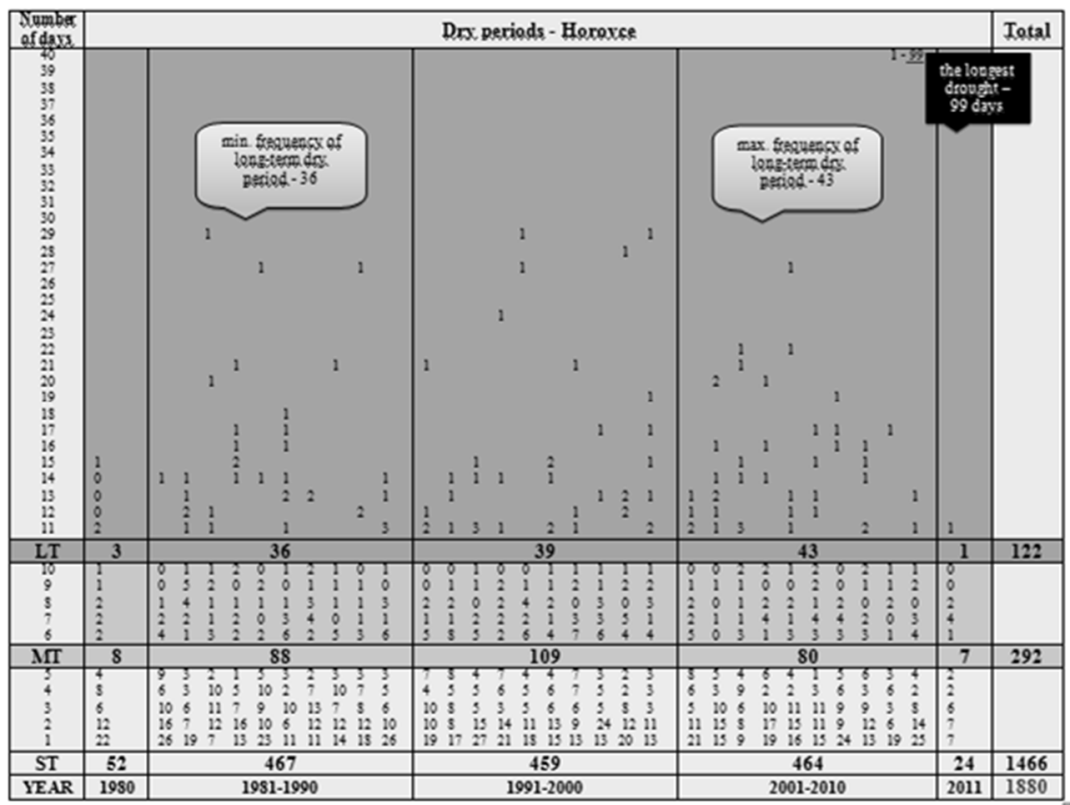

Figure 5: The frequency of droughts in the years 1980-2011, the station Horovce.

The absolute sum of the dry season for each station is illustrated in Figure 6. The graph shows that the most periods without precipitation were observed in the station Michalovce, the least in Horovce station with a difference of 104 times. The height difference between the two stations is only $6 \mathrm{~m}$ asl. From this it can be deduced that even at almost the same altitude and almost negligible distance between stations $(15 \mathrm{~km})$ in lowland area, the frequency of dry days is not the same. 


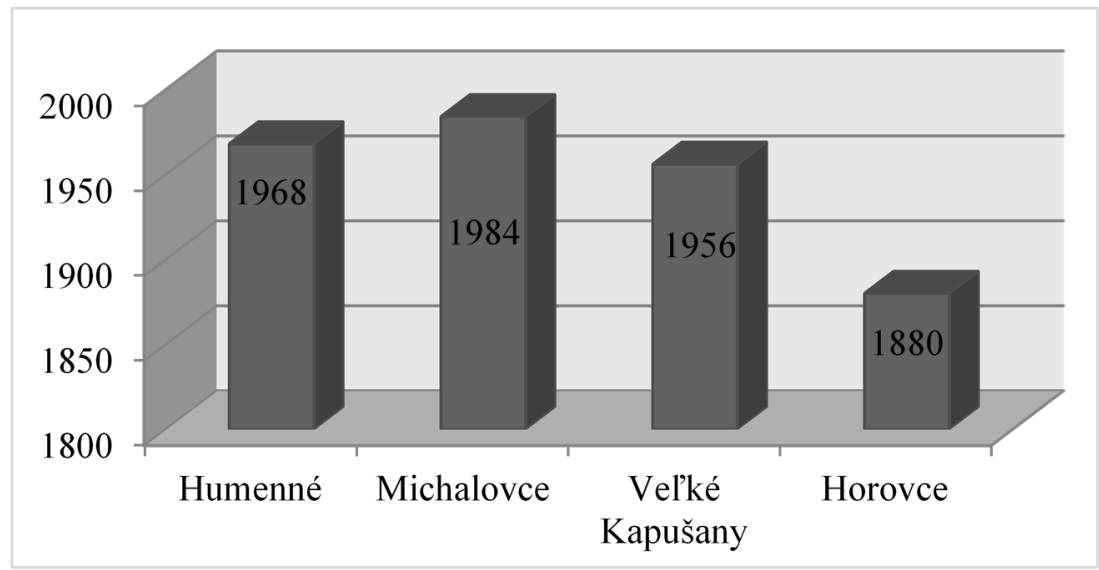

Figure 6: Absolute sum of the dry season for each station for the period 1980 to 2011.

\section{Conclusion}

The aim of this work was to emphasize the need for understanding and measuring precipitation, which most affects the level change of watercourses. If we know the amount of precipitation that falls on a certain area for a certain period of time, we can determine, for example, the most likely area of occurrence of floods, and thus the occurrence of the drought that are not just a concern of agriculture.

The selected four stations in Eastern Slovakia are at approximately the same altitude and in a distance of not more than $50 \mathrm{~km}$, and despite this fact measured rainfall totals as well as duration of dry periods differ highly. Differences between the dry and wet seasons for these stations ranged from 100 days.

We would like to point out the complexity of lowland areas, not only in Eastern Slovakia, where the major problem of flooding, which are most often caused by an outpouring of water from riverbeds due to infestation of large amounts of rainfall in a short period of time. The results of this work could be the basis for a proposal of water structures and measures to protect against excessive amounts of water. Long-term drought also has a negative impact on the country because the lack of water can cause damage to crops, deterioration of soil characteristics, limiting the use of water as an energy source or as a source of irrigation.

Monitoring the variability of dry and wet periods can lead to a proposal of appropriate measures, whether in the design of flood protection measures in problem areas or to draft the efficient use and management of water. Processing of measurements and assessment at other climatic stations could lead to a better understanding of precipitation ratios of our country if more economical and efficient use of water. 


\section{Acknowledgement}

The contribution is written thanks to support of project VEGA 1/0609/14. The Centre was supported by the Slovak Research and Development Agency under the contract No. SUSPP-0007-09.

\section{References}

[1] Paulson, E., Sadeghipour, J., Dracup, J.A., Regional frequency analysis of multiyear droughts using watershed and climatic information, Journal of Hydrology, Vol. 77, pp. 57-76, 1985.

[2] Bičárová, S. Čepčeková, E. Hlavatá, H. Extreme Precipitation and occurrence of wet and dry periods in mountain climate zones, In M Zelenakova (ed) Hydrologic risks - floods and droughts, Košice: FCE, TUKE, 2013.

[3] Parajka, J., Kohnová, S., Merz, R., Szolgay, J., Hlavčová, K., Blőschl, G., Comparative analysis of the seasonality of hydrological characteristics in Slovakia and Austria, Bratislava: SAV, 2009.

[4] Pekárová, P., Halmová, D., Miklánek, P., Pekár, J., Analysis of changes in $N$-return period of minimal flows in river Donau in river profile Bratislava in period 1876/77-2005/06 (in Slovak), Bratislava: SAV, 2008.

[5] Fischer, T., Gemmer, M., Lüliu, L., Buda, S., Temperatures and precipitation trends and dryness/wetness pattern in the Zhujiang River Basin in South China during 1961-2007, Quaternary International, Vol. 244, pp. 138-148, 2011.

[6] Zhang, K., Pan, S., Cao, L., Wang, Z., Zhang, W., Spatial distribution and temporal trends in precipitation extremes over the Hengduan Mountains region, China, from 1961-2012. Quaternary International, Vol. 247, pp. 1$11,2014$.

[7] Nastos, P.T., Zerefos, C.S., Spatial and temporal variability of consecutive dry and wet days in Greece. Atmospheric Research, Vol. 94, pp. 616-628, 2009.

[8] Villafuerte II, M.Q., Matsumoto, J., Akasaka, I., Takahashi, H.G., Kubota, H., Cinco, T.A., Long-term trends and variability of rainfall extremes in the Philippines. Atmospheric Research, Vol. 137, pp. 1-13, 2014.

[9] Kohnová, S., Lapin, M., Szolgay, J., Gaál, L., Methodology for the selection of 10-day maximum precipitation totals and their statistical analysis in the upper Hron region, Contributions to Geophysics and Geodesy, Vol. 35, No. 3, 2005.

[10] Szolgay, J., Parajka, J., Kohnová, S., Hlavčová, K., Comparison of mapping approaches of design annual maximum daily precipitation, Atmospheric Research, Vol. 92, No. 3, pp. 289-307, 2009.

[11] Zeleňáková, M., Purcz, P., Gargar, I., Hlavatá, H., Comparison of precipitation trends in Libya and Slovakia, In: River Basin Management 7, Southampton: WIT Press, pp. 365-374, 2013. 
[12] Zeleňáková, M., Purcz, P., Hlavatá, H., Gargar, I., Portela, M.M., Statistical Trends of Precipitation in Chosen Climatic Station in Slovakia and Libya, WSEAS Transactions on Environment and Development, Vol. 10, pp. 298305, 2014.

[13] Stračarová, M. 2014. Hydrological extremes - dry and wet periods (in Slovak). Thesis. Košice: FCE, TUKE, p. 55. 